suggestions for improving the quality of such clubs, but I could not find any that identified risks associated with this practice. I am happy to provide what in my knowledge is the first case-series report, based on anecdotal impressions, of such risks, with the knowledge and responsibility that it may generate a new field of research and debate or the definition of a journal club syndrome.

My experience suggests that the period preceding a journal club is directly associated with an increase of physical and mental health problems on presenting doctors, to an extent that makes it impossible to prepare for or deliver the presentation. Mental health problems include temporary cognitive deficits (mainly in the form of episodic memory loss that recovers with no intervention), manifested by a high number of doctors that have forgotten either that it was their day to present or to bring on the day the wrongly called memory sticks that carried all the data. In the latter case, further symptoms include the lack of alternative supporting methods and the common perception that stand-alone oral presentation cannot be delivered. Accidents, thefts and losses are also reported on a higher proportion in the pre-presentation period, to the point that health and safety regulation of journal clubs may become standard practice one day soon.

This evidence has been accumulated through many years of training and working in different areas, which suggests that the risk is not associated to specific grades of doctors, disciplines, environments, hospitals, trusts or geographical areas. As I continue to be surprised by the high quality of some presentations, mainly of very junior doctors, and challenged by their enthusiasm, I hope that this newly described syndrome does not present with associated apathy to others involved in the journal club.

gnasi Agell Consultant Psychiatrist and Associate Medical Director, South Staffordshire and Shropshire Healthcare NHS Foundation Trust, Cherry Orchard House, 39 Hospital Street, Tamworth B79 7EE, email: gnasi.agell@sssft.nhs.uk

doi: 10.1192/pb.33.10.396b

\section{The trouble with NHS psychiatrists}

St John-Smith et al provide a useful overview of the political imperatives which have shaped British psychiatry in the past 5 years, but as with other overviews $^{2}$ it is difficult for the reader to come away with any constructive message.

The authors rightly recognise the original New Ways of Working project as a practical response to a shortage of psychiatrists, but believe this has become a shorthand for cutting the number of medical staff and reducing the psychiatric orientation of the service. The national workforce figures suggest otherwise: between 1999 and 2007, the number of psychiatrists in England rose 3 by $46 \%$ and few can argue that recruitment is not vastly improved compared with 10 years ago.

The reality is that new services have grown even faster, with an estimated $\mathrm{f2}$ billion of additional investment since $1999,{ }^{3}$ mainly in specialist teams. The recruitment of medical staff and the establishment of suitable training placements have lagged behind, as outlined by the Audit Commission finding that almost a third of crisis resolution teams had no dedicated consultant sessions. ${ }^{4}$
It is inevitable, and many would argue desirable, that non-medical staff will be involved in front-line assessment, as they are now in most other branches of medicine. The solution is not to decry 'proforma tools and guidelines', but to argue for these to be used by suitably trained and supervised staff working in teams with ready access to psychiatrists, as originally envisaged in New Ways of Working. ${ }^{5}$ The College should lead on an overview of the medical staffing of specialist teams, and trusts and commissioners should be obliged to fund dedicated consultant sessions in order to meet their quality targets.

Although specialist teams provide some benefits, they have undoubtedly led to greater fragmentation of care and may not all survive beyond New Horizons. ${ }^{3}$ Our battle should be to ensure that the additional money which came with these teams is not clawed back in times of greater austerity.

St John-Smith P, McQueen D, Michael A, Ikkos G Denman C, Maier M, et al. The trouble with NHS psychiatry in England. Psychiatr Bull 2009: 33 : 219-25.

2 Craddock N, Antebi D, Attenburrow MJ, BaileyA, Carson A, Cowen P, et al. Wake-up call for British psychiatry. BrJ Psychiatry 2008; 193: 6-9.

3 Department of Health. New Horizons: Towards a Shared Vision for Mental Health. Department of Health, 2009.

4 National Audit Office. Helping People through Mental Health Crisis: The Role of Crisis Resolution and HomeTreatment Services, 2007.

5 CSIP/NIMHE, CWP, Royal College of Psychiatrists. New Ways of Working for Psychiatrists. Department of Health, 2005.

Judy A. Harrison Consultant Psychiatrist and Clinical Director, Manchester Mental Health and Social CareTrust, Chorlton House, 70 Manchester Road, Chorlton, Manchester M81 9UN, email: judy.harrison@mhsc.nhs.uk

doi: $10.1192 / p b .33 .10 .397$ 